\title{
Public support for global vaccine sharing in the COVID-19 pandemic: Intrinsic, material, and strategic drivers*
}

\author{
Ferdinand Geissler, Humboldt-Universität zu Berlin \\ Felix Hartmann, Humboldt-Universität zu Berlin \\ Macartan Humphreys, WZB Berlin Social Science Center/Columbia University \\ Heike Klüver, Humboldt-Universität zu Berlin \\ Johannes Giesecke, Humboldt-Universität zu Berlin
}

January 21, 2022

\begin{abstract}
As of early 2022 an estimated $50 \%$ of the global population is fully vaccinated for COVID-19 but the global distribution of vaccines is extremely unequal, over $85 \%$ vaccinated in the top 10 countries and below $3 \%$ in the bottom 10. Given that governments need to secure public support for investments in global vaccine sharing, it is important to understand the levels and drivers of public support for international vaccine solidarity. Using a factorial experiment administered to more than 10,000 online survey respondents in Germany, we show that global inequities are out of line with domestic German public opinion. Respondents are supportive of substantive funding amounts, on the order of the most generous contributions provided to date, though still below amounts that are likely needed for a successful global campaign. Public preferences appear largely to be driven by intrinsic concern for the welfare of global populations though are in part explained by material considerations - particularly risks of continued health threats from a failure to vaccinate globally. Strategic considerations are of more limited importance in shaping public opinion; in particular we see no evidence for free riding on contributions by other states. Finally, drawing on an additional survey experiment, we show that there is scope to use information campaigns highlighting international health externalities to augment public support for global campaigns.
\end{abstract}

\footnotetext{
*Research for this contribution is part of the Cluster of Excellence "Contestations of the Liberal Script" (EXC 2055, Project-ID: 390715649), funded by the Deutsche Forschungsgemeinschaft (DFG, German Research Foundation) under Germany’s Excellence Strategy. See data and replication material at https://wzb-ipi.github.io/vaccine_solidarity/
} 


\section{Introduction}

Vaccination is the key to overcome the COVID-19 pandemic. Multiple vaccines have been developed in record time and more than 9 billion doses have been administered globally to date. As of early 2022 an estimated $50 \%$ of the global population is fully vaccinated. However, the global distribution of the COVID vaccines is extremely unequal. Fewer than $1 \%$ of doses administered have been administered in low income countries. While about $85 \%$ of citizens are vaccinated in the ten countries leading in the COVID vaccination campaign, less than $3 \%$ of the population is vaccinated in the ten least performing countries. Strikingly, per capita GDP alone explains as much as $60 \%$ of the variation in vaccination rates; COVID mortality about $6 \%$ 1

Besides the evident inequities, and the economic and health threats to poorer countries (Egger et al., 2021), the unequal provision of vaccines has important consequences for wealthier countries and the international order (Barnett, 2020; Fazal, 2020; Lake, Martin and Risse, 2021). The risks from low global provision include economic and health threats arising from continued interruptions of global supply chains, and the preservation of reservoirs that facilitate disease mutation. One study estimates global costs at $\$ 9$ trillion Agarwal and Gopinath (2021). It has been estimated that approximately $70 \%$ of the worldwide population must be fully vaccinated to end the COVID-19 pandemic (Randolph and Barreiro, 2020). The delta variant has pushed the threshold for global herd immunity to $80 \%$ and potentially approaching 90\% (Barker et al., 2021). The rise of the Omicron variant cannot be stopped with the vaccines that are currently available, but at least the spread can be slowed down. Thus, vaccine inequity is not only a humanitarian disaster, it is one that has direct material consequences for wealthier countries.

Researchers at the International Monetary Fund (IMF) estimate the costs of global vaccination at $\$ 50$ billion (Agarwal and Gopinath 2021). Other estimates put costs closer to $€ 80$ billion. Though there is no clear determination of what a fair share is, as a benchmark, if the richest $25 \%$ of countries provided $€ 70$ per citizen this would sum to 80 billion Euros and imply contributions of about $€ 6$ billion for Germany and $€ 23$ billion for the United States. Using the Fair Share calculation, based on OECD guidelines, Germany's share of OECD donor shares would be $\$ 5 \mathrm{bn}(8 \%$ of $\$ 63 \mathrm{bn}){ }^{2}$ Given its size and wealth this is about four times the average corresponding contribution of other wealthy nations.

However, a fair distribution of COVID-19 vaccines is not only a matter of providing money, as vaccines continue to be scarce for some time. Despite the importance of globally distributing COVID-19 vaccines to stop the pandemic, a number of Western countries have launched campaigns for a third (in Israel even a fourth) booster vaccination in the wake of the Omicron wave which currently hits countries with full force (Mahase, 2021). Poorer countries will therefore continue to struggle to obtain sufficient vaccines for their citizens in the foreseeable future. On 4 August 2021, WHO director Tedros Adhanom Ghebreyesus therefore called for a moratorium halting COVID-19 vaccine boosters in favor of unvaccinated 3

Given that governments need to secure public support either for making large monetary contributions or for sharing vaccines with poorer countries, it is important to understand the levels and drivers of public support for global vaccine sharing and to identify ways through which governments can increase solidarity with other countries in need. Previous research has focused on ethical questions of global vaccine distribution (Emanuel et al., 2020, Jecker, Wightman and Diekema, 2021) or on mapping the international distribution of COVID-19 vaccines (e.g. Katz et al. | 2021| Massinga Loembé and Nkengasong, 2021). However, little is known about public opinion on global vaccine sharing. In this study we focus on three motivations: intrinsic motivations, material motivations, and strategic motivations. By intrinsic motivations we refer to the preferences for sharing that derive from concerns for the well-being of global populations. By material incentives we refer to the economic and health benefits to German citizens that might arise from a global response. To assess strategic motivations we draw on related literatures on contributions to global public goods. In particular, past work on European solidarity during the Eurozone crisis (Bechtel, Hainmueller and Margalit, 2017, Kuhn, Nicoli and Vandenbroucke, 2020 Kuhn, Solaz and van Elsas, 2018; | Stoeckel and Kuhn, 2018) and preferences for international climate agreements (Bechtel, Genovese and Scheve, 2019| Bechtel and Scheve, 2013), highlights how popular preferences are affected by both the specific costs and benefits for the donor country and the design of multilateral agreements. Building on this work we examine both the role of (stipulated) direct costs to Germany and the structure of international cooperation. We also assess the extent to which public support can be increased through information campaigns appealing to the self-interest of citizens.

Our results show that German citizens are supportive of generous contributions to the global distribu-

\footnotetext{
${ }^{1}$ Numbers calculated from data from Our World in Data; calculations available in replication materials.

${ }^{2}$ For details see Action and Hamilton (2021).

${ }^{3}$ Source: Reuters
} 
tion of vaccines against COVID-19. Median popular support is somewhat below estimated contributions needed to fund global vaccine redistribution; though average amounts exceed this. Popular preferences for global vaccine solidarity appear to primarily stem from humanitarian concerns and are only in part explained by material and strategic considerations. While there is a preference for multilateral efforts, public support for large contributions to global vaccine distribution does not depend on the behavior of other countries. We furthermore show that information campaigns can increase public support for international vaccine solidarity.

Overall the stark inequalities in global vaccine distribution are not in line with public opinion. Vaccine nationalism, though evident in policy, is a minority position. The results of our study have important implications for the current public debate on global vaccine distribution, but also for international solidarity and international cooperation more generally. On the one hand, the COVID-19 vaccination is a highly salient issue for all citizens worldwide and thus provides a unique opportunity to study popular preferences for international solidarity. On the other hand, since herd immunity is a global public good as the pandemic can only be overcome if all countries worldwide are immunized, our findings can furthermore inform the literature on preferences for international cooperation.

\section{Design}

Our analysis draws on data generated from a factorial survey experiment implemented as part of a fivewave panel study on vaccine attitudes that was fielded in Germany in 2021. We employ data primarily from wave 4 of the project which was administered to 10,525 respondents between 8 and 22 September 2021. In order to conduct the factorial survey experiment, we fielded the experiment relying on the online access panel of the survey company Respondi. All analyses were specified in a preregistered analysis plar ${ }^{4}$ and the study obtained IRB approval at Humboldt-Universität zu Berlin (HU-KSBF-EK_2021_0019).

In the experiment, participants first received an introductory text explaining the need for global vaccine sharing to overcome the pandemic. Afterwards, repondents were asked to consider a hypothetical scenario which randomly varied along four dimensions (health benefits, economic benefits, number of countries participating, contribution of other countries). Respondents were then asked to indicate how much Germany should contribute to global vaccine sharing, both in €and in vaccine doses. Each respondent received two vignettes successively.

More specifically, two dimensions focused on the benefits of global vaccine sharing for Germany in terms of public health and in terms of economic growth. One asked participants to imagine that "The risk of new mutations of the coronavirus increases considerably in Germany if there are no vaccinations in poorer countries"; a second asked participants to imagine that "The German economy shrinks by around $5 \%$ if there are no vaccinations in poorer countries." For each of these a control condition was provided in which there were no costs to Germany if there are no vaccinations in poorer countries.

The other two dimensions focused on the nature of multilateral agreements, asking participants to imagine settings in which 0,20 or 40 countries took part, contributing collectively $€ 0$, $€ 20$, or $€ 40$ billion. In all there are five types of agreement considered (because 0 participants implies 0 contributions and vice versa). In all this gives rise to a $2 \times 2 \times 5$ factorial design.

\section{Results}

\section{Levels of support for vaccine solidarity}

Figure 1 graphs raw data patterns to show the share of Germans supporting contributions of $€ X$ or less (top panel) or $X$ donations of vaccine doses (bottom panel) or less. We indicate, separately, preferred contributions when there are large economic and health costs of the status quo for Germany (versus none) and situations in which there is a major international deal (versus none).

We see that median favored contributions are around $€ 2$ bn and 100 million doses, an amount closely in line with actual current German commitments. There is considerable heterogeneity, however, with about one third support commitments around $€ 5$ bn or more. A small share - around 1 in 8 , support much larger contributions. Given the skewed nature of the distributions, the average amount proposed is much larger - around $€ 8$ bn Euros for cash, but the mean number of doses proposed is lower at around 80 million.

\footnotetext{
${ }^{4}$ The preregistered analysis plan is available at the Center for Open Science (https://osf.io/u5x3e).
} 

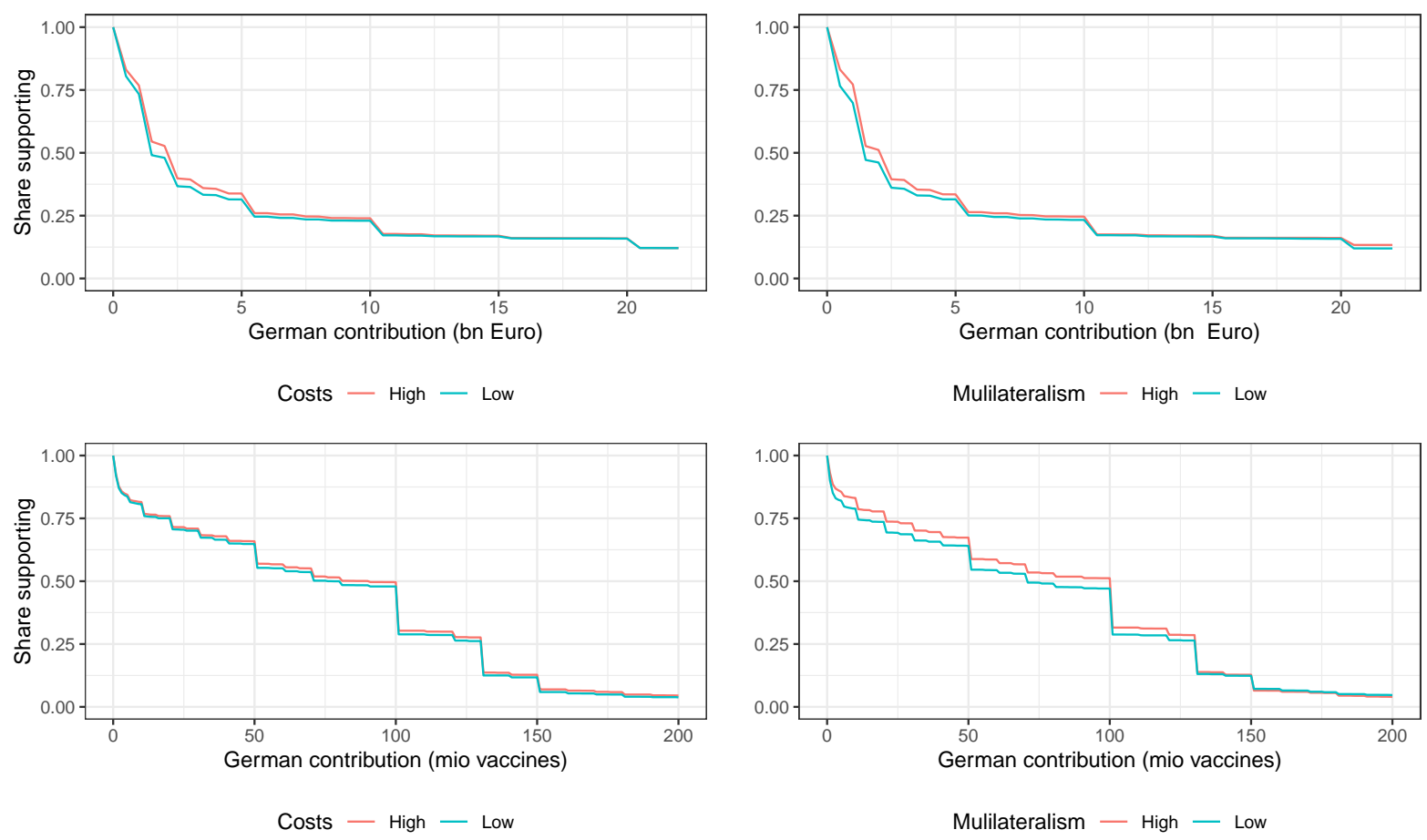

Figure 1: Distribution of support for contributions of different sizes

In the Supplementary Materials we document variation in these levels of support across subgroups. Based on preregistered analyses we show first, that support varies substantially as a function of political party support - with the greatest support among Green party voters and voters of the social democratic SPD whereas support is weakest among voters of the right-wing populist AfD. Second we show variation as a function of migration background, with substantially greater support for higher levels of solidarity among respondents with a migration background. We note nevertheless that despite this variation, support is high in all groups. To wit, a majority of AfD supporters, the group least likely to support international vaccine solidarity, still support contributions of 1 billion Euros or more.

\section{Treatment effects}

In Figure 1 we can also see that both sets of conditions increase the size of contribution supported by survey participants. These differences are generally statistically significant (see below) but as seen from the raw data, the effects are quantitatively small.

Figure 2 shows the marginal effects of all conditions on optimal cash donations and vaccine doses. This represents the same underlying patterns as seen in Figure 1 though the focus here is on average effects. Overall we see that both health risks and trading importance are statistically distinguishable from zero, but, as seen already, the magnitude of effects is not large.

Strikingly the amounts offered are positively responsive to amounts given by other countries, but unresponsive to the number of other countries giving. This is the opposite to what one might expect from accounts that focus on free-riding between states, and suggests, rather, a willingness to support initiatives regardless of average contributions by other countries.

Our heterogeneity analysis (in appendix) suggest that these treatment effects are quite similar for respondents that support different parties or that have different migration backgrounds.

\section{Structural analysis}

Preregistered structural estimation lets us shed more light on the intrinsic, material, and strategic motivations of respondents.

For this analysis we assume that individuals evaluate own country $\left(y_{i}\right)$ and other country $\left(\left(y_{j}\right)\right)$ contributions according to the objective function:

$$
u=(\alpha+\beta \times \text { economic risk }+\delta \times \text { health risk }) \times \log \left(\sum_{-i} y_{j}+y_{i}\right)-\gamma \times\left(y_{i}-\kappa \bar{y}\right)^{2}-y_{i}^{2}
$$




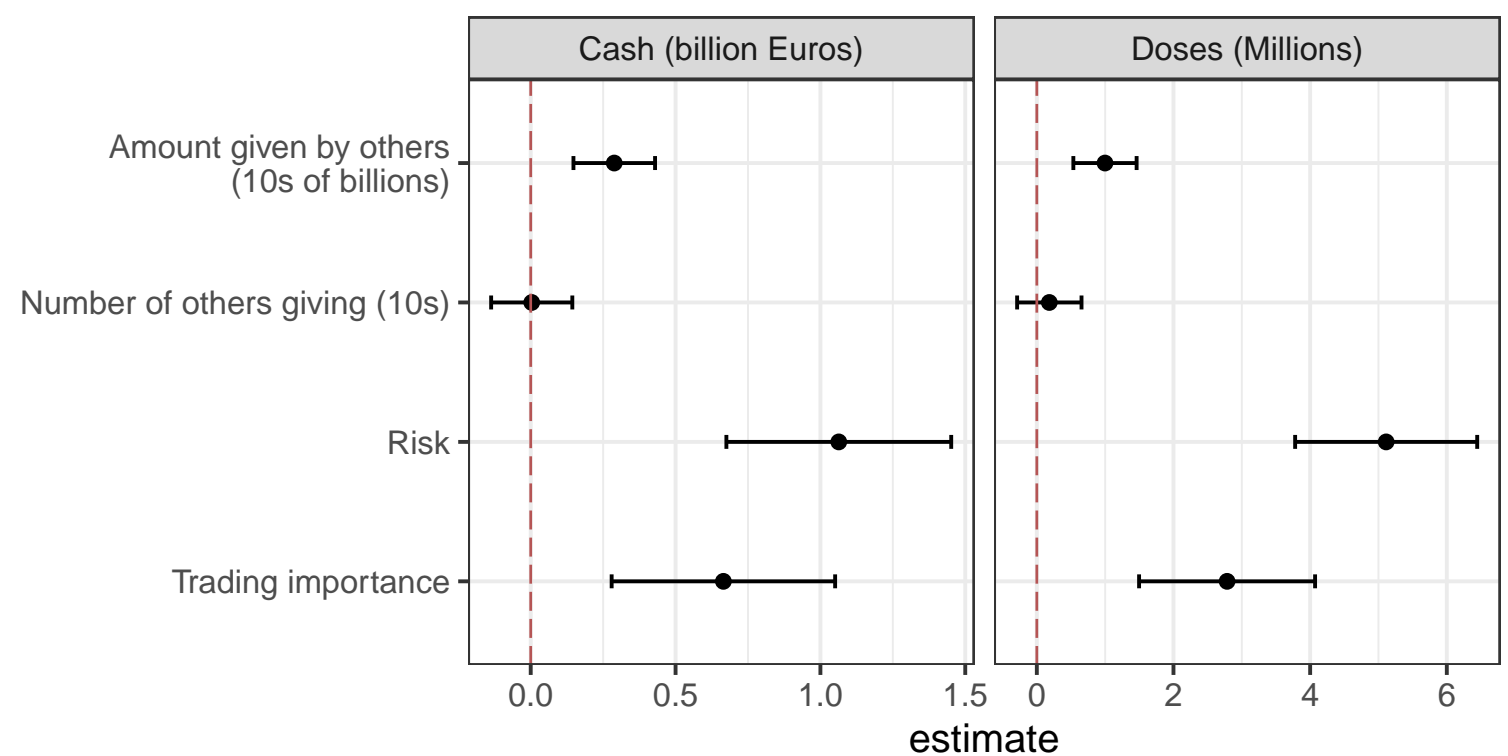

Figure 2: Marginal effects of conditions

where $\bar{y}$ is the average contribution of other states, and $\sum_{-i} j_{j}$ is the total contributions by others ${ }^{5}$

The function assumes diminishing marginal returns to total contributions, convex costs of own contributions, substitutibility of own and other contributions for global benefits, and a possible desire to benchmark contributions against the contributions of others. Letting $y_{i}^{*}$ denote optimal own contributions given economic and health risks and the contributions of others, we assume that players report $y_{i}^{*}+\epsilon_{i}$ where $\epsilon_{i} \sim N\left(0, \sigma^{2}\right)$.

We estimate parameters $(\alpha, \beta, \delta, \gamma, \kappa, \sigma)$ using maximum likelihood implemented via bbmle::mle2 in R. The estimated structural parameters are given in Table 1

Table 1: Structural parameter estimates

\begin{tabular}{crrrrrr}
\hline parameter & estimate & std.error & statistic & p.value & conf.low & conf.high \\
\hline$\alpha$ & 240.62 & 2.01 & 119.73 & 0.00 & 236.68 & 244.56 \\
$\beta$ & -10.32 & 12.71 & -0.81 & 0.42 & -35.23 & 14.59 \\
$\delta$ & 37.79 & 12.45 & 3.04 & 0.00 & 13.40 & 62.19 \\
$\gamma$ & 0.61 & 0.07 & 9.22 & 0.00 & 0.48 & 0.75 \\
$\kappa$ & 5.22 & 0.40 & 13.06 & 0.00 & 4.44 & 6.00 \\
$\sigma$ & 15.98 & 0.08 & 205.18 & 0.00 & 15.83 & 16.14 \\
\hline
\end{tabular}

We see here strong evidence for marginal gains from contributions independent of economic and health risks $(\alpha)$, these marginal gains are increased $(\delta)$ when there are substantial health risks (by about 16\%), but are not much affected by economic risks $(\beta)$. Respondents place weight on alignment with other countries $(\gamma)$, but the results on $\kappa$ suggest that they target contributions that are significantly higher (five times higher) than the average amount given by other nations. Note that average contributions by other countries was not provided directly to respondents, though it can be calculated from the numbers and the amounts given. The implied factor of 5 is remarkably close - and somewhat higher - than the factor of 4 that we calculated using the fair share calculation.

Overall these results support the conclusions that German citizens see intrinsic benefits from global contributions, that these are augmented, but do not depend on externalities - health externalities in particular - and that Germans, insofar as they benchmark contributions to those of other nations, do not support free riding and indeed value contributing at rates higher than those of other wealthy nations.

\footnotetext{
${ }^{5}$ We note that this expression differs from the expression in our pre-analysis plan in not subscripting parameters by respondent.
} 


\section{Discussion}

Overall our findings suggest high levels of support for contributions to address global vaccine inequity that stem from intrinsic, material, and, less forcefully, strategic rationales. Two pieces of additional analysis provide support for these conclusions. One provides direct evidence for humanitarian motivations and a second provides direct behavioral evidence for responsiveness to global risks.

First, we interpret the high rates of giving in the control conditions - when there are no health or economic benefits stipulated - as evidence of non-strategic humanitarian concerns. To measure humanitarian motivations directly we included in the survey (wave 2 and wave 4 ) a question asking respondents to indicate how the German government should prioritize to ensure vaccination for an older Indian woman as compared to a younger German woman. The comparison directly pits nationalist concerns against humanitarian concerns. Importantly also, we expect, any strategic considerations that enter in the decision to prioritize an Indian woman should apply a fortiori to the prioritization of a German woman. Strikingly, we find that $57 \%$ of the respondents place the priority of the older Indian woman as high or higher than the German woman, and $38 \%$ even place it strictly higher.

Second, we interpret the results on health and economic costs as indicative of strategic considerations. These considerations are in principle manipulable. For this, we rely on a second experiment implemented in wave 2. All analyses were specified in a preregistered analysis plar ${ }^{6}$ and the study obtained IRB approval at Humboldt-Universität zu Berlin (HU-KSBF-EK_2021_0010). 7 Participants were randomly assigned to a treatment group that is exposed to a video explaining the benefits of global vaccine sharing and a control group which did not see the video. The video emphasizes in particular the risk of more mutations forming if vaccines are not made available in developing countries. Subsequently, respondents were asked whether they support the international distribution of vaccines (attitudinal outcome) and were offered the opportunity to donate money to UNICEF which was put in charge for global vaccine sharing (behavioural outcome). More specifically, respondents earned 75 so-called "Mingle Points" cents in token appreciation for their participation in the survey (this corresponds to 0.75 Euros). We offered them 50 additional Mingle Points and gave them the following choice. They could either keep the 50 Mingle Points for themselves or donate all or part of them to UNICEF for the worldwide distribution of Corona vaccines. For every point they donated, we donated 1.5 Euro Mingle points to UNICEF (see Table 2 in the Supplementary Materials).

Consistent with the findings presented above we found evidence for quite high baseline willingness to contribute. The median contribution is $40 \%$ and the most common response - chosen by about a third of respondents - was to contribute the full amount of this funding to UNICEF. Figure 3 reports the results of the information experiment. We find that respondents in the treatment group that were exposed to the video are significantly more likely to show solidarity both with regard to the attitudinal and the behavioural outcome. More specifically, the reported willingness to personally support international distribution of vaccines is 0.069 units higher than in the control group. In a similar vein, the average actual donations that respondents made to UNICEF were on significantly higher in the treatment than in the control group (with about $4 \%$ or respondents more likely to donate the full amount to UNICEF).

Before concluding, we discuss a set of plausible threats to validity. The first relates to a set of critique in Diamond and Hausman (1994) that highlights difficulties that respondents have in providing numeric valuations of public goods. Focusing on contingent valuation surveys in Economics, Diamond and Hausman (1994) highlight risks that respondents may not have well defined valuations of public goods, may not be in a position to take relevant budget constraints into account (which can lead to what is sometimes called an embedding effect), and provide answers that cannot easily be assessed against revealed preferences. Although our experiment bears similarities with contingency valuation surveys our aim here is not to assess individual willingness to pay for global vaccinations, but rather to assess what policies respondents would like to see public officials follow. Their report of these preferences to us, which in turn get communicated publicly, albeit in aggregated form, bears a direct relation to the policy quantities of interest which is absent for contingency valuation surveys; by the same token, embedding effects may indeed be real in the formulation of policy priorities. However, this does not imply a bias in measurement, but rather a threat of inconsistencies in policy demands.

Although the aim of our study is different to those of scholars assessing the valuation of public goods, we still recognize that survey responses may not accurately predict the policy preferences that would advocate in a policy context when the benefits and costs of different strategies are debated by political

\footnotetext{
${ }^{6}$ The preregistered analysis plan is available at the Center for Open Science https://osf.io/69mpy).

${ }^{7}$ We only present results for the personal donation outcome since the conjoint had a flawed design. For full transparency we present results of the conjoint in the Supplementary Materials.
} 


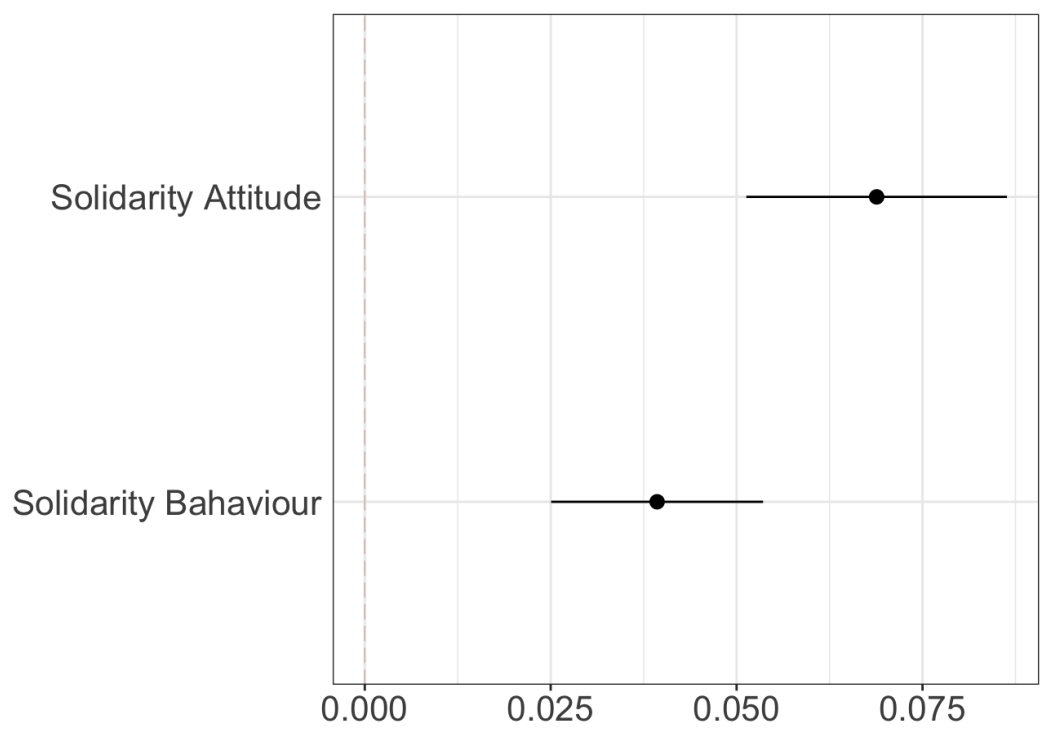

Figure 3: Effect of video treatment on individual solidarity

actors, and responses may be sensitive to question wording, for instance, or the information we supplied to contextualize costs. Fully addressing these questions would require implementing a field analogue of our study, perhaps involving discussions between politicians and citizens (Wuttke and Foos, 2021).

\section{Conclusions}

Our findings have clear implications for the current debate on international vaccine solidarity in the COVID pandemic. With regard to the instruments of achieving a fair allocation of vaccines globally, the evidence presented in Figures 1 and 2 shows that patterns of support for monetary and dose donations are similar. However, the value of median preferred dosage donations (around 100 million doses) is substantively smaller than the median preferred cash donations. This is in part an artifact of the fact that dosage donations by Germany are capped by vaccine holdings; nevertheless it highlights the fact that framing sharing in terms of vaccines rather than cash, by suggesting a zero sum nature of the problem, may yield weaker support for sharing. There are, however, many other avenues to address vaccine inequality including strategies that target production in developing countries, through financing, extending intellectual property rights, and sharing know-how.

Our study also has important implications for the debate on international solidarity (Bechtel, Hainmueller and Margalit, 2017, Kuhn, Nicoli and Vandenbroucke, 2020, Kuhn, Solaz and van Elsas, 2018, Stoeckel and Kuhn, 2018) and global public goods (Bechtel, Genovese and Scheve, 2019; Bechtel and Scheve, 2013). We show that public support for international solidarity in global vaccine sharing is positively affected by the amounts given by other countries which corroborates the findings from previous research on global climate cooperation and EU bailouts (Bechtel, Hainmueller and Margalit, 2017 , Bechtel and Scheve, 2013). However, there is no evidence for free-riding as citizen support is not conditional on the number of other countries participating in global vaccine, on contrast to findings on public attitudes towards global climate agreements (Bechtel and Scheve, 2013). Finally, our study adds to the current debate by showing that governments could increase support for international solidarity through information campaigns.

While efforts to share vaccines globally have been a failure to date, the evidence we provide importantly suggests that this is not due to lack of public support for the proposition. Average proposals exceed current contributions by the German government and also exceed fair share calculations of what the German government ought to be providing. Median proposals are somewhat less than the fair share benchmark, but nevertheless large. Evidence from our experiment with ancillary data suggest that strategic considerations matter, but are not paramount in explaining public preferences. Rather humanitarian rationales loom large. In all, these results suggest that policy-makers who take up the mantel of addressing the challenge of achieving global vaccination will have the moral support of the public behind 
them. 


\section{References}

Action, CARE and Booz Allen Hamilton. 2021. The case for U.S. investment in global COVID-19 vaccinations. Technical report Care.

Agarwal, Ruchir and Gita Gopinath. 2021. "A proposal to end the COVID-19 pandemic." Staff Discussion Notes 2021(004).

Barker, Pierre, David Hartley, Andrew F Beck, George "Holt" Oliver, Bhargavi Sampath, Thomas Roderick and Steve Miff. 2021. "Rethinking Herd Immunity: Managing the Covid-19 Pandemic in a Dynamic Biological and Behavioral Environment." NEJM Catalyst Innovations in Care Delivery 2(5).

Barnett, Michael. 2020. "COVID-19 and the Sacrificial International Order." International Organization

Bechtel, Michael M., Federica Genovese and Kenneth F. Scheve. 2019. "Interests, Norms and Support for the Provision of Global Public Goods: The Case of Climate Co-operation." British Journal of Political Science 49(4):1333-1355.

Bechtel, Michael M., Jens Hainmueller and Yotam Margalit. 2017. "Policy design and domestic support for international bailouts." European Journal of Political Research 56(4):864-886.

Bechtel, Michael M. and Kenneth F. Scheve. 2013. "Mass support for global climate agreements depends on institutional design." Proceedings of the National Academy of Sciences of the United States of America 110(34):13763-13768.

Diamond, Peter A and Jerry A Hausman. 1994. "Contingent valuation: is some number better than no number?" Journal of economic perspectives 8(4):45-64.

Egger, Dennis, Edward Miguel, Shana S Warren, Ashish Shenoy, Elliott Collins, Dean Karlan, Doug Parkerson, A Mushfiq Mobarak, Günther Fink, Christopher Udry et al. 2021. "Falling living standards during the COVID-19 crisis: Quantitative evidence from nine developing countries." Science Advances 7(6):eabe0997.

Emanuel, Ezekiel J., Govind Persad, Adam Kern, Allen Buchanan, Cécile Fabre, Daniel Halliday, Joseph Heath, Lisa Herzog, R. J. Leland, Ephrem T. Lemango, Florencia Luna, Matthew S. McCoy, Ole F. Norheim, Trygve Ottersen, G. Owen Schaefer, Kok Chor Tan, Christopher Heath Wellman, Jonathan Wolff and Henry S. Richardson. 2020. "An ethical framework for global vaccine allocation.".

Fazal, Tanisha M. 2020. "Health Diplomacy in Pandemical Times." International Organization .

Jecker, Nancy S, Aaron G Wightman and Douglas S Diekema. 2021. "Vaccine ethics: an ethical framework for global distribution of COVID-19 vaccines." Journal of Medical Ethics 47(5):308-317.

URL: https://jme.bmj.com/content/47/5/308

Katz, Ingrid T., Rebecca Weintraub, Linda-Gail Bekker and Allan M. Brandt. 2021. "From Vaccine Nationalism to Vaccine Equity Finding a Path Forward." New England Journal of Medicine 384(14):12811283.

Kuhn, Theresa, Francesco Nicoli and Frank Vandenbroucke. 2020. "Preferences for European unemployment insurance: a question of economic ideology or EU support?" Journal of European Public Policy $27(2): 208-226$.

Kuhn, Theresa, Hector Solaz and Erika J. van Elsas. 2018. "Practising what you preach: How cosmopolitanism promotes willingness to redistribute across the european union." Journal of European Public Policy 25(12):1759-1778.

Lake, David A., Lisa L. Martin and Thomas Risse. 2021. "Challenges to the Liberal Order: Reflections on International Organization." International Organization 75(2):225-257.

Mahase, Elisabeth. 2021. "Covid-19: Countries dump vaccines as demand slumps and sharing proves difficult." BMJ p. n1893. 
Massinga Loembé, Marguerite and John N. Nkengasong. 2021. "COVID-19 vaccine access in Africa: Global distribution, vaccine platforms, and challenges ahead." Immunity 54(7):1353-1362.

URL: https://www.sciencedirect.com/science/article/pii/S1074761321002612

Randolph, Haley E and Luis B Barreiro. 2020. "Herd immunity: understanding COVID-19." Immunity 52(5):737-741.

Stoeckel, Florian and Theresa Kuhn. 2018. "Mobilizing Citizens for Costly Policies: The Conditional Effect of Party Cues on Support for International Bailouts in the European Union." Journal of Common Market Studies 56(2):446-461.

Wuttke, Alexander and Florian Foos. 2021. "Making the Case for Democracy.". 


\section{Supplementary Materials}

\section{Contents}

\begin{tabular}{|l|l}
\hline A Experiment Design & 2
\end{tabular}

A.1 Assignment . . . . . . . . . . . . . . . . . . . . . . . . . . 2

A.2 Outcomes . . . . . . . . . . . . . . . . . . . . . . . . 3

B Information Experiment Design 5

B.1 Outcome: Willingness to share $\ldots \ldots \ldots \ldots \ldots \ldots \ldots \ldots$

B.2 Outcome: Personal donation $\ldots \ldots \ldots \ldots \ldots \ldots \ldots$

\begin{tabular}{ll}
\hline C Pre-registered subgroup analyses & 6
\end{tabular} 


\section{A Experiment Design}

We implement a $2 \times 2 \times 5$ factorial design.

We lead with introductory text:

The following is about vaccination progress in Germany and the rest of the world.

The vaccination campaign against the coronavirus in Germany is now well advanced and anyone who wanted to be vaccinated could do so. The benefits of a third booster vaccination are currently being discussed. In contrast, many other, poorer countries are still at the very beginning with vaccinations and almost no one there has received a single vaccination yet.

A total of around 11 billion vaccine doses are needed to vaccinate all people around the world who are ready to vaccinate. Although the production of vaccines is in full swing, there is currently not enough vaccine available to carry out the first and second vaccinations in the poorer countries and the third vaccination in the richer countries at the same time

Variations are then as follows:

\section{Z1: Trading importance}

- 0 Control: It has no negative impact on the German economy if there are no vaccinations in poorer countries.

- 1 Treatment: The German economy shrinks by around 5\% if there are no vaccinations in poorer countries.

\section{Z2: Risk}

- 0 Control: The risk of new mutations of the coronavirus does not increase noticeably in Germany if there are no vaccinations in poorer countries.

- 1 Treatment: The risk of new mutations of the coronavirus increases considerably in Germany if there are no vaccinations in poorer countries.

\section{Z3: Deal}

- 0 Control: There is no international deal on the global distribution of vaccines to poorer countries.

- 1 Treatment: There is an international deal on the global distribution of vaccines to poorer countries. 20 other countries are involved in the agreement, which together contribute a total of 20 billion euros.

- 2 Treatment: There is an international deal on the global distribution of vaccines to poorer countries. 40 other countries are involved in the agreement, which together contribute a total of 20 billion euros.

- 3 Treatment: There is an international deal on the global distribution of vaccines to poorer countries. 20 other countries are involved in the agreement, which together contribute a total of 40 billion euros.

- 4 There is an international deal on the global distribution of vaccines to poorer countries. 40 other countries are involved in the agreement, which together contribute a total of 40 billion euros.

Note that $Z 3$ can itself be interpreted as a $2 * 2+1$ sub design that can be coded into:

- Z4: 0, 20, 40 other countries

- Z5: 0, 20, 40 billion provided by others

\section{A.1 Assignment}

Each subject sees two conditions, producing a total of $20 \times 19=380$ versions, assigned independently. 


\section{A.2 Outcomes}

Subjects are asked about amounts of vaccines that Germany should share and financial contributions Germany should make in each condition.

Outcome 1:

The total costs to meet global vaccination needs amount to around 70 billion euros. A contribution from Germany of one billion euros to this fund would cost the population in Germany the equivalent of around 12 euros per person.

For each of the two scenarios, please indicate how many euros Germany should contribute to this fund for global vaccination. (Options range from 0 to 70 billion; Millions can be specified, separated by commas (e.g. 0.1 billion for 100 million))

- Vignette 1 ..billion Euro

- Vignette 2 ..billion Euro

Outcome 2:

Germany will still have around 200 million vaccine doses available by the end of the year. If Germany wanted to offer all of its citizens a third vaccination, Germany would have to reserve around 70 million of these vaccine doses.

For each of the two scenarios, please indicate what proportion of these 200 million vaccine doses Germany should contribute to the global distribution of vaccine doses to poorer countries. (Options range from 0 to $200 \mathrm{~m}$ )

- Vignette 1 ...million doses

- Vignette 2 ..million doses

See Figure 4 for a screenshot of the experiment, as seen by respondents. 
Mittlerweile ist die Impfkampagne gegen das Coronavirus in Deutschland weit fortgeschritten und alle, die sich impfen lassen wollten, konnten dies tun. Aktuell wird bereits über den Nutzen einer dritten Booster-Impfung gesprochen. Demgegenüber stehen viele andere, ärmere Länder mit den Impfungen noch ganz am Anfang und fast niemand dort hat bislang eine Impfung erhalten.

Insgesamt werden ungefähr 11 Milliarden Impfdosen benötigt, um weltweit alle impfbereiten Menschen zu impfen. Obwohl die Produktion von Impfstoffen auf Hochtouren läuft, ist momentan nicht genügend Impfstoff vorhanden, um gleichzeitig die Erst- und Zweit-Impfungen in den ärmeren Ländern und die Dritt-Impfung in den reicheren Ländern vorzunehmen.

Stellen Sie sich folgende Situation vor:

- Die deutsche Wirtschaft schrumpft um etwa $5 \%$, wenn in den ärmeren Ländern keine Impfungen stattfinden.

- Die Gefahr durch neue Mutationen des Coronavirus erhöht sich in Deutschland erheblich, wenn in den ärmeren Ländern keine Impfungen stattfinden.

- Es gibt ein internationales Abkommen zur weltweiten Verteilung von Impfstoffen an ärmere Länder. An dem Abkommen sind 40 andere Länder beteiligt, die zusammen insgesamt 20 Milliarden Euro beitragen.

Die Kosten, um den weltweiten Impfbedarf abzudecken belaufen sich insgesamt auf ca. 70 Milliarden Euro. Ein Beitrag Deutschlands von einer Milliarde Euro zu diesem Fond würde die Bevölkerung in Deutschland umgerechnet etwa 12 Euro pro Person kosten.

Mit wie viel Euro sollte sich Deutschland an diesem Fond zur weltweiten Impfung beteiligen? (Sie können Ihre Antwort in Miliarden und/oder Millionen angeben; Antwortbereich: 0-70 Milliarden \& 0-999 Millionen.)

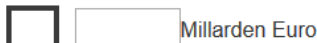

Millarden Euro

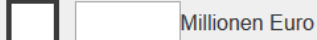

Bis Ende des Jahres wird Deutschland noch etwa 200 Millionen Impfdosen zur Verfügung haben. Wenn Deutschland allen seinen Bürgern eine dritte Impfung anbieten möchte, müsste Deutschland etwa 70 Millionen Impfdosen davon reservieren.

Wäre die Situation wie im grauen Kasten beschrieben, welchen Anteil dieser 200 Millionen Impfdosen sollte Deutschland zu der weltweiten Verteilung von Impfdosen an ärmere Länder beitragen? (Antwortbereich: 0 bis 200 Millionen)

Millionen Impfdosen

Figure 4: Screenshot of the interface 


\section{B Information Experiment Design}

The information experiment was implemented in Wave 2. The experiment was introduced with the following text:

- Introductory text: And now we come to the topic of the global vaccination campaign. The pandemic can only be defeated if it is brought under control globally. In the fight against Covid19, the provision of vaccines is particularly important. The COVAX platform was set up under the leadership of the World Health Organization (WHO) for the acquisition and fair distribution of vaccines.

The treatment, assigned to half of the participants, was a video produced by Deutsche Welle. Deutsche Welle is Germany's foreign broadcaster which is organized under public law and financed by federal tax revenues. The video can be viewed here: https://www.dw.com/de/impfstoff-f\%C3\% BCr-entwicklungsl\%C3\%A4nder/av-56554104

\section{B.1 Outcome: Willingness to share}

Attitudinal outcome: Would you be willing to personally support the international distribution of vaccines?

1. Yes

2. No

\section{B.2 Outcome: Personal donation}

- Personal donation: You can also contribute to the global distribution of the vaccines yourself. UNICEF is working on behalf of the COVAX initiative to ensure that the corona vaccines are made available to people in the poorest countries.

Next to the 75 Mingle points that you receive for taking part in this survey, you will receive an additional 50 Mingle points from us. You can either keep these points yourself or donate all or part of them to UNICEF for the worldwide distribution of corona vaccines. For every mingle point you donate, we donate 1.5 mingle points to UNICEF.

Please select how the additional Mingle points should be allocated to you or UNICEF.

Table 2: Bonuses and donations

\begin{tabular}{lll}
1 & 0 Mingle Points & 75 Mingle Points \\
2 & 10 Mingle Points & 60 Mingle Punkte \\
3 & 20 Mingle Points & 45 Mingle Points \\
4 & 30 Mingle Points & 30 Mingle Points \\
5 & 40 Mingle Points & 15 Mingle Points \\
6 & 50 Mingle Points & 0 Mingle Points \\
\hline
\end{tabular}

- Donations go here: https://www.unicef.de/spenden/jetzt-spenden?purpose=235762 


\section{Pre-registered subgroup analyses}

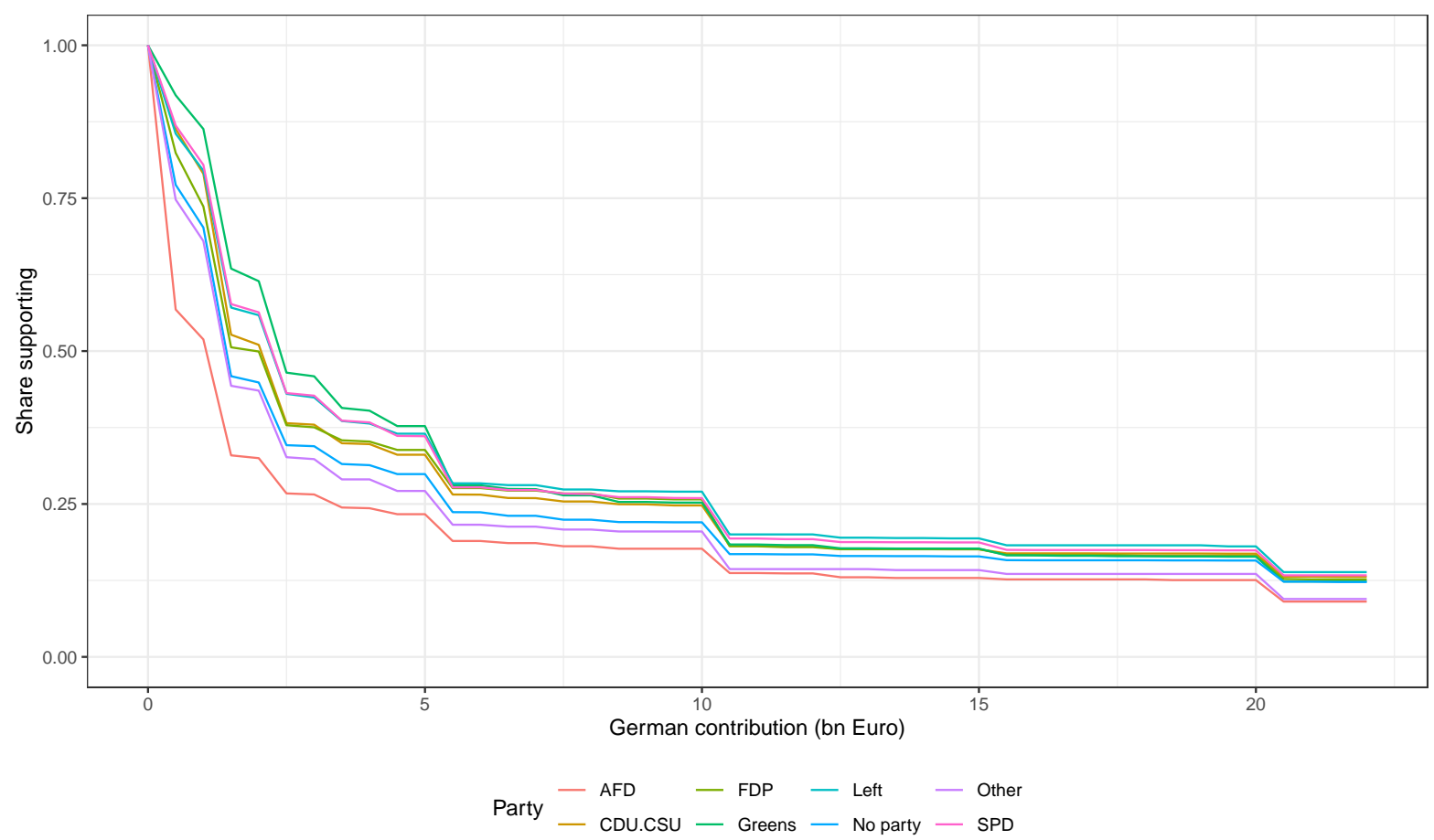

Figure 5: Levels of support by party

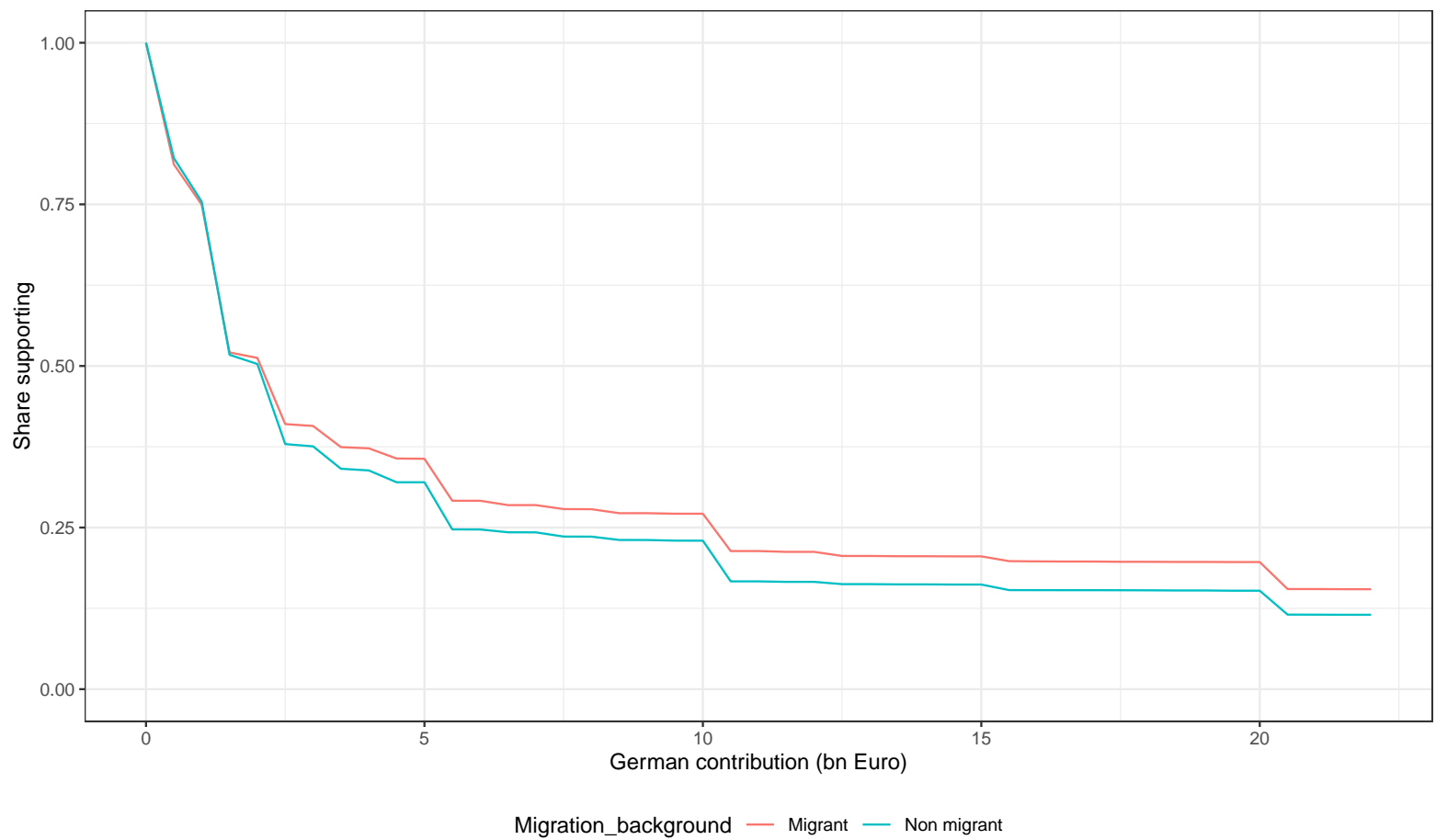

Figure 6: Levels of support by migration background 


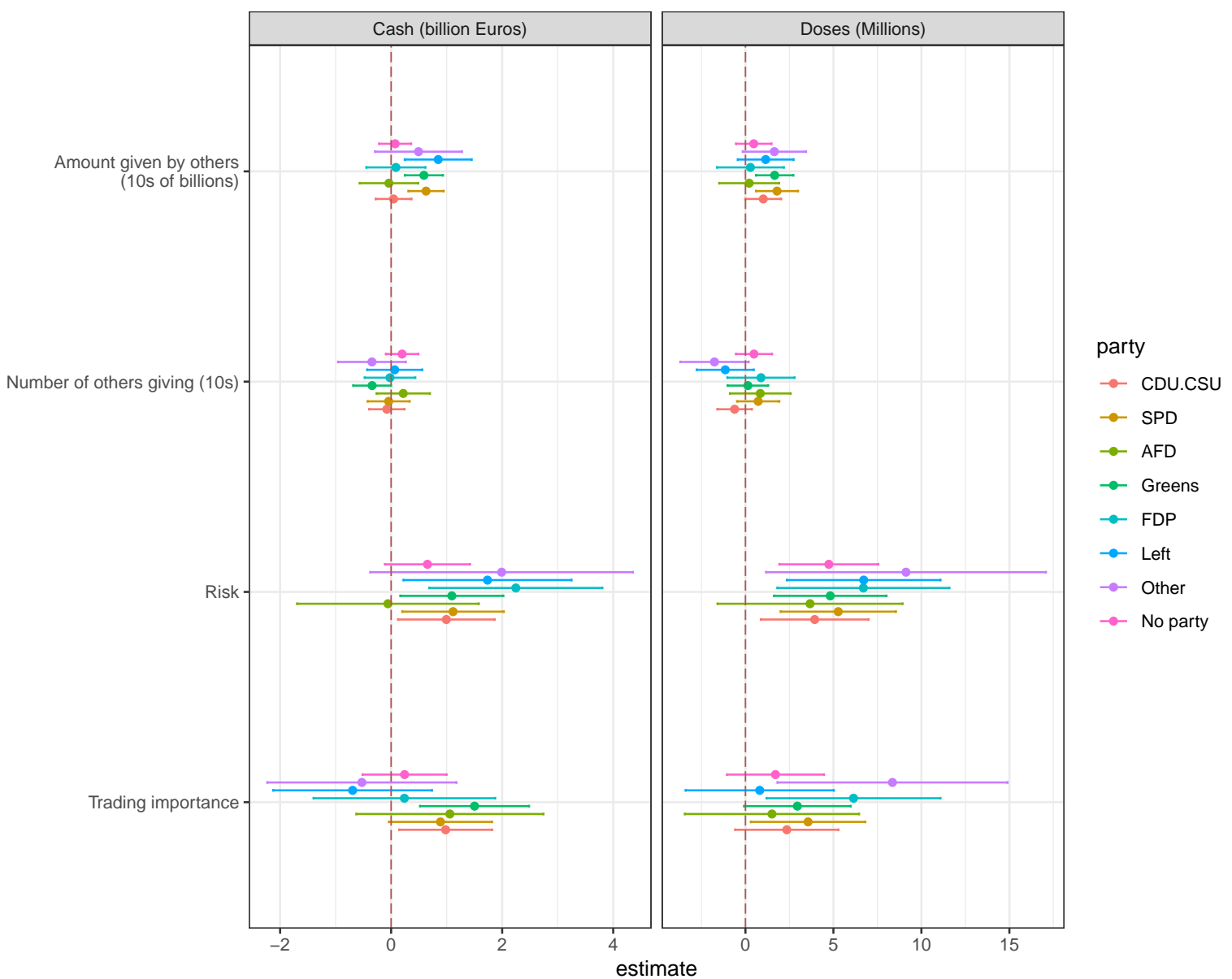

Figure 7: Marginal effects of conditions by party

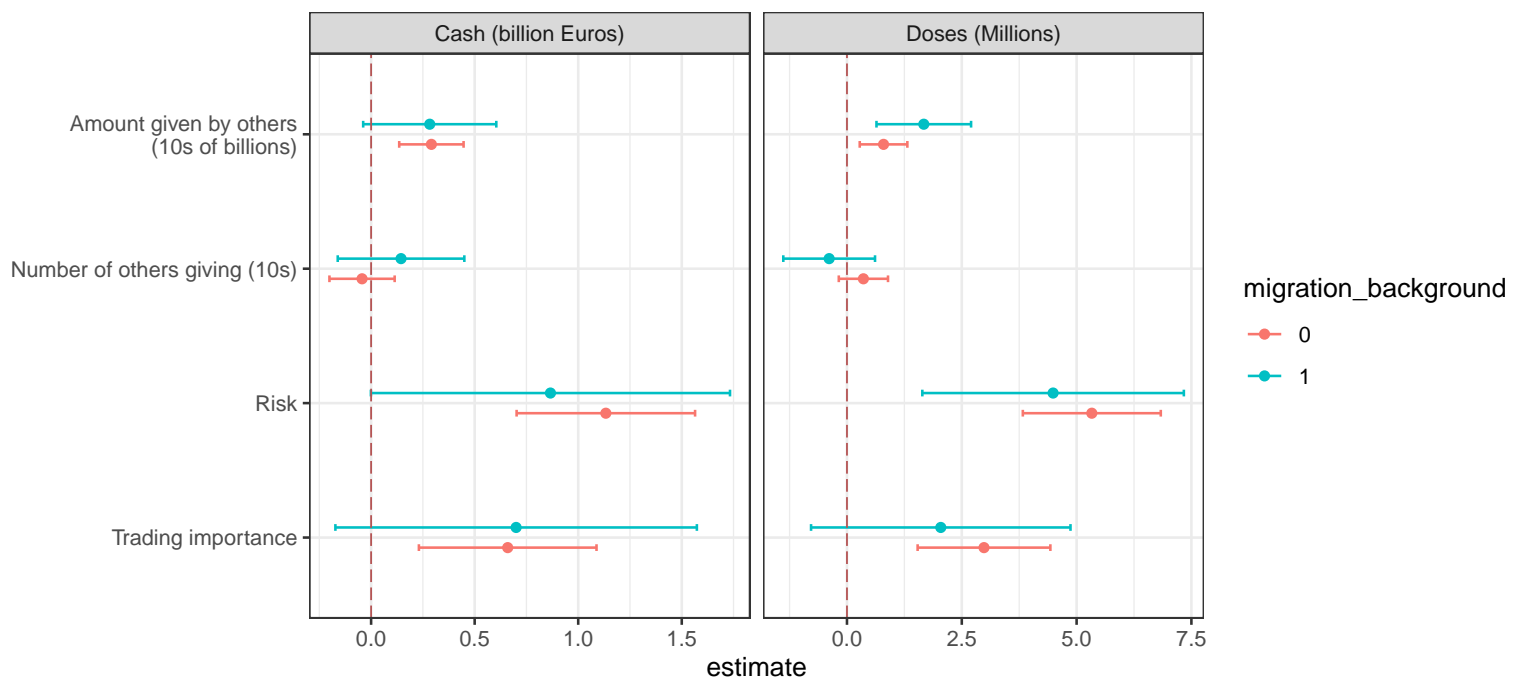

Figure 8: Marginal effects of conditions by migration background 